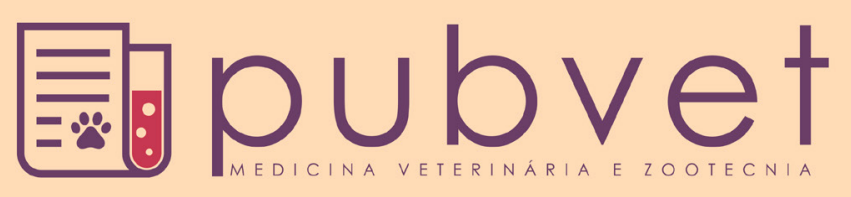

HTTP://DX.DOI.ORG/10.22256/PUBVET.V11N6.538-544

\title{
Problemas sanitários das pisciculturas brasileiras
}

\section{Matheus Hernandes Leira ${ }^{1 *}$, Lucas Silva Reghim ${ }^{2}$, Lívia da Silva Ciacci ${ }^{1}$, Luciane Tavares da Cunha ${ }^{1}$, Hortência Aparecida Botelho ${ }^{3}$, Mirian Silvia Braz ${ }^{4}$, Natália Pereira Dias $^{5}$, Carlos Cicinato Vieira Melo ${ }^{6}$}

${ }^{1}$ Professor e Pesquisador do Centro Universitário do Sul de Minas - UNIS-MG.

${ }^{2}$ Discente do Curso de Medicina Veterinária, Iniciação Científica - UNIS-MG

${ }^{3}$ Mestre e Doutoranda pela Universidade Federal de Goiás - UFG

${ }^{4}$ Mestre e Doutoranda pela Universidade Federal de Lavras - UFLA

${ }^{5}$ Discente do Curso de Medicina Veterinária - Centro Universitário do Sul de Minas - UNIS-MG

${ }^{6}$ Professor substituto e Pesquisador do Instituto Federal Baiano - IFB - Campus Santa Inês - BA

*Autor para correspondência: matheus.hernandes@unis.edu.br

RESUMO. O conhecimento das doenças, o controle do uso de drogas, da alimentação, da qualidade de água e da presença de agentes patogênicos em todas as etapas do processo de produção aquícola é fundamental para a obtenção de produtos de boa qualidade e proteção da saúde pública, assim como para espécies terrestres, a sanidade é um dos aspectos mais relevantes para a produção comercial de animais aquáticos. Os riscos do surgimento de enfermidades aumentam proporcionalmente à elevação das densidades de estocagem de animais, da quantidade de alimento oferecido, de excretas produzidas, dos manejos e transportes frequentes. A flutuação dos parâmetros de qualidade da água em sistemas aquícolas gera estresse, que afeta o sistema imunológico dos peixes deixando-os susceptíveis ao ataque de patógenos.

Palavras chaves: Doenças em peixes, policultivo, animais aquáticos

\section{Health problems of Brazilian fish farms}

ABSTRACT. Knowledge of diseases, control of drug use, food, water quality and the presence of pathogens in all stages of the aquaculture production process is fundamental for obtaining good quality products and protection of public health, As well as for terrestrial species, sanitation is one of the most relevant aspects for the commercial production of aquatic animals. The risks of disease onset increase proportionally to the increased stocking densities of animals, the amount of food offered, excreta produced, handling and frequent transport. The fluctuation of water quality parameters in aquaculture systems generates stress, which affects the immune system of fish leaving them susceptible to attack by pathogens.

Keywords: Fish diseases, polyculture, aquatic animals

\section{Problemas sanitarios de las pisciculturas brasileñas}

RESUMEN. El conocimiento de las enfermedades, el control del consumo de medicamentos, la nutrición, la calidad del agua y la presencia de agentes patógenos en todas las etapas del proceso de producción de la acuicultura es fundamental para obtener productos de buena calidad y protección de la salud pública, así como las especies terrestres, la salud es uno de los aspectos más importantes para la producción comercial de los animales acuáticos. El riesgo de aparición de enfermedades crece proporcionalmente al aumento de las densidades de carga animal, la cantidad de comida que se ofrece, de los 
excrementos producidos, las gestiones y el transporte frecuente. La fluctuación de los parámetros de calidad del agua en los sistemas de acuicultura genera estrés, lo que afecta el sistema inmunológico peces dejándolos susceptibles al ataque de patógenos.

Palabras clave: enfermedades de los peces, el policultivo, animales acuáticos

\section{Introdução}

As pisciculturas são uma atividade que visa o cultivo racional de peixes, envolve planejamento adequado para uma boa produção e uma série de custos diretos e indiretos, além disso, a piscicultura apresenta grande relevância social e econômica para a ampliação da produção de alimentos, podendo também contribuir com a conservação da diversidade biológica de ambientes naturais.

Doenças comprometem sobremaneira o bom desempenho zootécnico dos animais gerando prejuízos consideráveis ao piscicultor, dentre as doenças, as de origem bacteriana são as principais responsáveis pelas perdas em piscicultura comercial. No entanto, doenças a vírus são igualmente avassaladoras e muito difíceis de controlar uma vez instaladas na população.

Dentre as bactérias potencialmente patogênicas para peixes destacam-se as Aeromonas móveis, Flavobacterium columnare e Streptococcus agalactiae. Em Minas Gerais e no Brasil os controles dessas doenças têm sido feitos somente pelo uso de antibióticos incorporados à ração (para animais em engorda), ou administrados diretamente na água de cultivo para tratamento de alevinos. Em ambientes aquáticos, essas drogas ocasionam grande impacto no ambiente, associado a resíduos químicos na água, bem como a seleção de bactérias resistentes. Ainda, nos últimos anos, os resíduos de antibióticos em carcaças de peixes têm sido uma barreira ao comércio internacional, principalmente o destinado à exportação para os Estados Unidos e Comunidade Europeia.

Parasitos e fungos, por sua vez, são responsáveis pela perda de grande número de larvas e alevinos. Algumas doenças de peixes são zoonoses, assim, diversos helmintos podem ser contraídos pelo homem através da ingestão de peixes infectados.

Bactérias como Streptococcus e Mycobacterium, por exemplo, podem infectar pessoas que lidam direta e frequentemente com peixes abrigando tais patógenos.

Entre as espécies exóticas que o Brasil utiliza como fonte de economia, a tilápia do Nilo apresenta grandes vantagens competitivas em relação às nativas (Lizama et al., 2007). Tal fato pode ser explicado, em parte, não somente pela rusticidade que caracteriza a espécie, como também pelo fato de já existirem informações detalhadas sobre suas características biológicas e zootécnicas, as quais podem ser aproveitadas em condições de cultivo (Fernandes, 2014). Destacam-se, dentre as suas principais características: curto ciclo de produção, rápido crescimento, tolerância a ambientes superpovoados, consome de alimento natural, bem como de rações balanceadas e resíduos agropecuários de origem animal e vegetal, ótima qualidade de carne, ausência de mioespinhas, facilidade de filetamento e industrialização da carcaça, boa aceitação do filé no mercado consumidor e resistência ao manejo e às doenças.

Atualmente são reconhecidas mais de 70 espécies de tilápias provenientes de três diferentes gêneros: Oreochromis Günther, 1889, Sarotherodon Rüppell, 1852 e Tilapia Smith, 1840 (Zanolo and Yamamura, 2006). Entretanto, apenas as variedades do gênero Oreochromis conquistaram destaque na aquicultura mundial, como: a tilápia de Moçambique, Oreochromis aureus Steindachner, 1864; a tilápia de Zambibar, Oreochromis urolipis hornorum Trewavas, 1966; e a tilápia do Nilo, $O$. niloticus, sendo esta última, a mais criada em todo mundo devido a sua ótima adaptação ao cativeiro (Kubitza, 1999, Kubitza, $\underline{2009)}$.

\section{Principais problemas relacionados à sanidade em piscicultura}

A piscicultura está mais evidente no Brasil desde 1904, no setor de comercialização, quando se deu os primeiros passos para essa atividade no país que com o passar dos anos, a atividade intensificou-se juntamente com os problemas que também foram surgindo, dificultando a vida dos piscicultores brasileiros.

Por ser uma prática em alguns aspectos nova, os piscicultores vêm enfrentado dificuldades, como de financiamentos e principalmente de colocação de seus produtos no mercado, mas mesmo assim, o país ainda é um dos maiores produtores de pescados em cativeiro, mesmo 
diante de uma representação modesta no cenário mundial. Essa é uma situação que poderia ser diferente se os piscicultores tivessem maiores incentivos, uma realidade presente em todo país, em que alguns piscicultores exercem outras atividades para complementar sua renda.

A piscicultura brasileira passa por uma fase de consolidação e expansão inquestionáveis e nos últimos anos, ocorreu marcada expansão de empreendimentos conhecidos como "pesquepague". Esses são utilizados para a pesca esportiva, atividade social e econômica de relevância nos países desenvolvidos.

No sistema de produção intensiva, como por exemplo, a criação de peixes em tanques-rede, é utilizada altas densidades de estocagem, sendo comuns neste tipo de exploração problemas de manejo, má qualidade da água, questões nutricionais, entre outros (Kubitza, 1999, Kubitza, 2009). Estes fatores de estresse ambiental refletem-se na homeostasia dos peixes, predispondo-os ao ataque de organismos patogênicos (Dias et al., 2008).

Esses agentes, em tais condições de estresse, podem desencadear surtos epizoóticos graves e dizimar criações inteiras em poucos dias. Tal situação ocorre principalmente devido ao descaso com as medidas preventivas na introdução de peixes novos e também pela presença de peixes selvagens parasitados.

Dentre as bactérias potencialmente patogênicas para peixes destacam-se as Aeromonas móveis, Flavobacterium columnare e Streptococcus agalactiae. Em Minas Gerais e no Brasil o controle dessas doenças tem sido feito somente pelo uso de antibióticos incorporados à ração (para animais em engorda), ou administrados diretamente na água de cultivo para tratamento de alevinos. Em ambientes aquáticos, essas drogas ocasionam grande impacto no ambiente, associado a resíduos químicos na água, bem como a seleção de bactérias resistentes.

Descrições mais antigas consideram esses patógenos como oportunistas atualmente essas bactérias foram relatadas como emergentes agentes primários, possuindo mecanismos altamente específicos para promoção de doenças. $O$ gênero Aeromonas compreende um grupo de organismos que têm amplamente distribuídas em ambientes aquáticos. Adaptadas ao crescimento em temperaturas que variam de $5^{\circ} \mathrm{C}$ a $37^{\circ} \mathrm{C}$, esses são bastonetes Gram-negativos, oxidase positivos, anaeróbicos facultativos e estão presentes na superfície e brânquias dos peixes. A taxonomia deste grupo sofreu muitas alterações nas últimas décadas e até o presente momento a caracterização das espécies por testes bioquímicos e métodos moleculares não estão totalmente padronizados, havendo ainda muitas controvérsias. Aeromonas sp são as principais causadoras de doenças em peixes, que em conjunto são denominadas de "septicemia por aeromonas moveis". Essas são chamadas de móveis pois apresentam motilidade por flagelos polares e laterais. Os sinais clínicos de infecção podem variar de lesões de pele, superficiais ou profundas, a quadros típicos de septicemia. As lesões de pele podem se apresentar como áreas de hemorragia e necrose de extensão variada, que podem progredir para úlceras que acometem geralmente o tecido muscular. Nos quadros de infecção sistêmica são observados a exoftalmia, abdômen distendido contendo líquido serosanguinolento e presença de petéquias hemorrágicas nas vísceras (Pavanelli et al., 2002).

A columnariose é uma doença de distribuição mundial que acomete a maioria das espécies de peixes de água doce, altamente impactante, é a segunda enfermidade que mais causa prejuízos à indústria americana do "catfish" No Brasil não existem dados sobre seu impacto na produção de peixes; porém, surtos da doença são frequentemente observados nas pisciculturas nacionais, principalmente nas larviculturas. Flavobacterium columnare é o agente etiológico dessa doença, fenotipicamente essa bactéria é caracterizada como um bastonete longo, Gram negativo, móvel, forma colônias filamentosas de coloração amarelada (produz um pigmento denominado flexirubina) e não cresce em meios de cultura convencionais. A sintomatologia clínica da doença é caracterizada pela erosão da pele e nadadeiras, com a evolução do quadro (24-48 horas após) ocorre o acometimento de tecidos adjacentes, causando necrose muscular e destruição total das nadadeiras (Arias et al., 2004).

As bactérias do gênero Streptococcus são patogênicas para uma ampla gama de hospedeiros, dentre eles seres humanos, peixes de água doce e marinhos. As infecções causadas por esses microrganismos são impactantes para diversos segmentos da produção animal, incluindo a aquicultura. Esses ocasionam enormes prejuízos principalmente para a tilapicultura mundial. Infecções causadas Streptococcus agalactiae vem sendo descritas na literatura desde meados do século 30. Também conhecido como 
Streptococcus do Grupo B, essa bactéria é um importante patógeno para seres humanos estando associado a casos de meningoencefalites em recém-nascidos, e em bovinos, esse microrganismo é responsável por quadros de mamite clínica e subclínica. Nas últimas décadas essa bactéria tem se destacado como patógeno emergente na piscicultura. Casos de infecção por essa bactéria foram descritas em mais de 20 espécies de peixes (Olivares-Fuster et al., 2008).

A introdução desses agentes em uma propriedade livre ocasiona um impacto devastador na criação, com morbidade e mortalidade elevadas, que pode dizimar o plantel. Os fatores predisponentes são os mesmos das demais doenças bacterianas em peixes (estresse, variação brusca na temperatura da água, excesso de amônia, alta densidade de estocagem, baixa qualidade de água etc.). A doença pode ocorrer na forma de abscessos multifocais na musculatura dos animais, denominada de "gulf ball disease" ou de maneira clássica (septicêmicos e meningoencefalites). Os principais sinais clínicos são abscessos multifocais ("gulf ball disease"), natação errática e em rodopios, exoftalmia unilateral ou bilateral, perda de escamas, escurecimento do tegumento, anorexia, excitabilidade e morte. Após alta mortalidade inicial, a doença atinge um quadro endêmico no plantel (Bader et al., 2003).

Os processos fotossintéticos do fitoplâncton e a respiração dos organismos aquáticos (plâncton, peixes, bentos e microrganismos) causam flutuações diuturnas na concentração de oxigênio e gás carbônico dissolvidos na água. Em sistemas aquaculturais de água parada ou de pequena renovação de água, a excessiva entrada de nutrientes via alimento ou adubação favorece o desenvolvimento de uma densa população planctônica, acentuando ainda mais as flutuações nos níveis de oxigênio dissolvido. Baixas concentrações de oxigênio dissolvido combinadas à níveis elevados de gás carbônico são frequentemente observados durante o período noturno, prejudicando o desenvolvimento normal ou, até mesmo, causando massiva mortalidade de peixes. A aeração dos tanques e viveiros é fundamental para a manutenção de níveis adequados de oxigênio dissolvido, aumentando a sobrevivência e desempenho produtivo dos peixes.

Os estudos relativos à patologia e parasitologia de peixes são campos de crescente importância no contexto da piscicultura mundial. Parece ser inevitáveis que as populações mundiais se tomem cada vez mais dependentes da cultura artificial de peixes, enquanto que as populações naturais destes se reduzem paulatinamente pela pesca predatória.

Desse modo, as parasitoses têm, muitas vezes, consequências importantes, mas não tão evidentes: diminuição da eficiência de assimilação (o que implica um maior gasto de alimento) e da taxa de crescimento, aumento da suscetibilidade dos animais parasitados a infecções por agentes oportunistas, nomeadamente os fungos, bactérias e vírus.

Os animais parasitados não são boas fontes alimentares para as dietas das pessoas, tanto em qualidade, como em quantidade, pois as mortes por enfermidades ictioparasitárias podem diminuir muito as quantidades alimentares disponíveis para abastecer uma população. Deste modo, um peixe pode constituir-se uma excelente fonte de proteínas e de outras substâncias, mas se for proveniente de um animal parasitado, enfraquecido e com seu metabolismo alterado pela presença de parasitas, torna- se pobre e insuficiente como fonte alimentar. Vale ressalta a importância do caráter zoonótico que as enfermidades de peixes podem ter. Atualmente, dá-se maior ênfase às doenças provenientes de contaminações por organismos microbianos ou suas toxinas, havendo pouca ênfase às zoonoses ou doenças adquiridas pela ingestão de animais que abrigam estes parasitas.

Os parasitas mais comuns que podem ser ingeridos no consumo de alimentos derivados de peixe cru, malcozido ou não congelado, infectado, relatam-se os helmintos, preferencialmente trematódeos e nematódeos. Os trematódeos são subdivididos nas classes causadoras de infecções hepáticas, intestinais e pulmonares. Semelhantemente, os nematódeos são divididos em causadores de doença preferencialmente intestinais e agentes de infecção extras intestinais.

Peixes e moluscos são hospedeiros naturais de grande variedade de parasitas. Em geral, estes parasitas podem ser destruídos pela cocção adequada do alimento, permanecendo o risco de infecção no consumo de frutos do mar crus, em conserva, ou malcozidos.

Com a globalização e aumento do comércio internacional gerado pela economia moderna, o maior número de viagens internacionais $\mathrm{e}$ a 
disponibilidade de frutos do mar frescos de áreas litorâneas do mundo inteiro, nas quais parasitas são endêmicos, provocaram aumento na estatística de infecções nos Estados Unidos e Europa, onde casos de doenças transmissíveis pelo consumo de peixe e molusco crus eram tradicionalmente raros No Brasil, apesar de não haver estatística oficial, sabe-se que muitos casos de enfermidades de peixes são registrados nas regiões onde ocorre grande oscilação de temperatura, regiões Sul e Sudeste (Fontaine, 1985).

$\mathrm{Na}$ piscicultura, devem-se adotar medidas adequadas para controlar a propagação de doenças ictioparasitológicas, mediante atestado ictiosanitário para disciplinar o transporte de peixes de um local para outro, comprovando que determinada piscicultura apresenta-se sadia e evitando a disseminação de doenças entre as espécies.

A chave para o sucesso do tratamento da doença bacteriana é o diagnóstico precoce e o tratamento preciso. Se o tratamento for retardado, pode levar a perdas substanciais. Isto é particularmente relevante para os tanques de que por diversas razões, muitas vezes são suscetíveis a surtos de doenças bacterianas.

Importantes patógenos virais emergentes de peixes pertencem a famílias de vírus dos vertebrados (homem e animais domésticos). No entanto, existem diferenças significativas entre a ecologia de doenças virais písceas e as humanas ou de outros vertebrados terrestres.

Os vírus afetam principalmente as primeiras fases de vida dos peixes e, portanto, ovos, larvas e alevinos são mais susceptíveis. Os ovos infectados podem produzir peixes, recém eclodidos, com sinais clínicos da enfermidade, enquanto os peixes adultos ao se infectarem podem ou não apresentar qualquer sintoma.

Nas regiões de águas quentes, os vírus não constituem os principais patógenos, a não ser o herpes vírus do peixe gato $\mathrm{e} o$ vírus da bronquionefrite das enguias, que provocam alterações clínicas graves, porém permanecem limitados à suas regiões geográficas, o primeiro nos EUA e, o segundo, no Extremo Oriente (Kinkelin et al., 1984). Portanto, a sua disseminação deve ser impedida mediante medidas profiláticas severas.

As infecções gerais podem ser causadas por rabdovírus, herpesvirus e iridovirus, os rabdovírus abrigam os principais vírus: da viremia primaveral da carpa (VPC); da septicemia hemorrágica viral (SHV); da necrose hematopoiética infecciosa (NHI), entre outros.

A aquicultura pode ser uma atividade tradicional de pequena escala com pouca intervenção humana ou com sofisticadas operações industriais em que os animais são criados e gerenciados de forma a se obter um ótimo desempenho e a máxima produtividade.

Houve intensificação, nos últimos anos, do interesse dessa atividade, devido a uma diminuição da pesca, esse aumento de criatórios, entretanto, propiciou $\mathrm{o}$ aparecimento $\mathrm{e}$ desenvolvimento de algumas enfermidades, principalmente em função do confinamento. Além disso, concentrações elevadas de peixes favorecem o aparecimento de doenças em surtos epizoóticos por patógenos que têm, portanto, sua transmissão facilitada, em condições ambientes naturais esses patógenos não seriam de grandes expressões.

$\mathrm{O}$ regime de confinamento, a alta densidade dos animais, manejos de cultivo e degradação da água por produtos tóxicos ou de excreção podem provocar um estresse crônico, os peixes, assim, tornam-se imunossuprimidos e, portanto, menos resistentes às infecções.

A qualidade de água é de vital importância conhecer as características físicas, químicas e biológicas da água, pois os peixes dependem da água para realizar todas as suas funções, ou seja: respirar, se alimentar, reproduzir e excretar. Para um bom desenvolvimento dos organismos aquáticos e uma produção economicamente viável, tem que ter certo controle da água dos viveiros onde são cultivados, os parâmetros de qualidade de água são físicos, químicos e biológicos. Os parâmetros físicos são divididos em Temperatura e transparência (cor, Turbidez e sólidos), os parâmetros químicos são, oxigênio dissolvido, pH, Amônia e salinidade e os parâmetros Biológicos são coliformes e algas, os peixes influenciam na qualidade da água por meio de processos como eliminação de dejetos e respiração (Leira et al., 2017).

A quantidade de ração fornecida também influencia diretamente na qualidade da água; ao ser oferecido grande quantidade de alimento aos peixes, ocorrerá à poluição do tanque. $\mathrm{O}$ conhecimento para se analisar e interpretar os resultados dos parâmetros da qualidade da água é de grande importância para os piscicultores. 
Fatores como oxigênio dissolvido e temperatura, entre outros, estão diretamente relacionados com o desenvolvimento dos peixes (Mallasen et al., 2008).

As infecções por Aeromonas móveis são de ocorrência mundial e provavelmente a doença bacteriana mais comum em peixes de água doce. Essas possuem como fatores predisponentes diversas condições de estresse as quais podem ser submetidas as populações de peixes, como o excesso de matéria orgânica na água, oxigênio dissolvido abaixo das concentrações adequadas e alta densidade animal.

\section{Reconhecendo peixes doentes}

É possível que algumas doenças sejam "diagnosticadas" pela observação do comportamento dos peixes e por sinais externos como nadadeiras erodidas, equimoses e feridas na pele, exoftalmia, presença de parasitos e outros.

Porém, frequentemente são necessários investigações e exames completos para um diagnóstico apurado. Vários tipos de patógenos podem atuar concomitantemente no mesmo hospedeiro, assim o profissional deverá identificar o causador primário da doença e, então, decidir sobre a melhor forma de intervenção.

\section{Conclusão}

Doenças se constituem na maior causa de prejuízos econômicos em aquicultura comercial. Peixes são animais altamente sensíveis ao estresse, condição essa praticamente inevitável em aquicultura intensiva. Uma vez doentes peixes têm seu desempenho zootécnico negativamente impactado, tornam-se susceptíveis ao ataque maciço de patógenos, o que se traduz em prejuízos irreparáveis ao produtor. Em piscicultura, para manter enfermidades fora do sistema, a melhor estratégia é acreditar e adotar programas de prevenção e controle. Por outro lado, conhecer as principais doenças passíveis de acometer peixes torna profissionais e aquicultores melhor preparados para tomar decisões adequadas frentes aos surtos.

\section{Referências Bibliográficas}

Arias, C. R., Welker, T. L., Shoemaker, C. A., Abernathy, J. W. \& Klesius, P. H. 2004. Genetic fingerprinting of Flavobacterium columnare isolates from cultured fish. Journal of Applied Microbiology, 97, 421-428.
Bader, J. A., Shoemaker, C. A. \& Klesius, P. H. 2003. Rapid detection of columnaris disease in channel catfish (Ictalurus punctatus) with a new species-specific 16-S rRNA gene-based PCR primer for Flavobacterium columnare. Journal of Microbiological Methods, 52, 209220.

Dias, P. G., Furuya, W. M., Pavanelli, G. C., Machado, M. H. \& Takemoto, R. M. 2008. Carga parasitária de Rondonia rondoni, Travassos, 1920 (Nematoda, Atrictidae) e fator de condição do armado, Pterodoras granulosus, Valenciennes, 1833 (Pisces, Doradidae). Acta Scientiarum. Biological Sciences, 26, 151-156.

Fernandes, A. S. 2014. Amostragem de Ectoparasitos de Tilápia do Nilo Oreochromis niloticus (Linnaeus, 1758) em cultivo comercial.

Fontaine, R. E. 1985. Anisakiasis from the American perspective. JAMA, 253, 1024-1025.

Kinkelin, P., Bernard, J. \& HattenbergerBaudouy, A. M. 1984. Immunization against viral diseases occurring in cold water. Symposium on Fish Vaccination. Paris.

Kubitza, F. 1999. Nutrição e alimentação dos peixes cultivados, Campo Grande, Mato Grosso do Sul.

Kubitza, F. 2009. Manejo na produção de peixes. Panorama da Aqüicultura, 19, 14-23.

Leira, M. H., Cunha, L. T., Braz, M. S., Melo, C. C. V., Botelho, H. A. \& Reghim, L. S. 2017. Qualidade da água e seu uso em pisciculturas. PUBVET, 11, 11-17.

Lizama, M. d. 1. A. P., Takemoto, R. M., RanzaniPaiva, M. J. T., Silva, A. L. M. \& Pavanelli, G. C. 2007. Relação parasito-hospedeiro em peixes de pisciculturas da região de Assis, Estado de São Paulo, Brasil. 1. Oreochromis niloticus (Linnaeus, 1757). Acta Scientiarum. Biological Sciences, 29, 223-231.

Mallasen, M., Barros, H. P. \& Yamashita, E. Y. 2008. Produção de peixes em tanques-rede e a qualidade da água. Revista Tecnologia \& Inovação Agropecuária, 1, 47-51.

Olivares-Fuster, O., Klesius, P. H., Evans, J. \& Arias, C. R. 2008. Molecular typing of Streptococcus agalactiae isolates from fish. Journal of Fish Diseases, 31, 277-283. 
Pavanelli, G. C., Eiras, J. C. \& Takemoto, R. M. 2002. Doenças de peixes: profilaxia, diagnóstico e tratamento. Eduem, Maringá.

Zanolo, R. \& Yamamura, M. H. 2006. Parasitas in tilapia of nile in fresh water net-tank system. Semina: Ciências Agrárias, 27, 281-288.
Article History:

Received 6 March 2017

Accepted 10 April 2017

Available on line 11 May 2017

License information: This is an open-access article distributed under the terms of the Creative Commons Attribution License 4.0, which permits unrestricted use, distribution, and reproduction in any medium, provided the original work is properly cited. 